\title{
Influence of branching density on the cross-linkability of ethylene-octene copolymers
}

\author{
Sameepa Poongavalappil ${ }^{1}$, Petr Svoboda ${ }^{1}$, Rajesh Theravalappil ${ }^{1}$, Dagmar Svobodova ${ }^{2}$, Toshiaki Ougizawa ${ }^{3}$ and \\ Tomas Sedlacek ${ }^{1}$
}

Ethylene-octene copolymers (EOCs) with two different octene contents (20 and $35 \mathrm{wt} \%$ ) and the same melt flow index ( $3 \mathrm{~g}$ per $10 \mathrm{~min}$ ) were cross-linked using various levels $(0.3,0.5$ and $0.7 \mathrm{wt} \%$ ) of dicumyl peroxide at different temperatures. Cross-linking and degradation were analyzed by rubber process analyzer (RPA) within a temperature range of $150-200^{\circ} \mathrm{C}$. The highest $\mathrm{s}_{\text {max }}$ (maximum elastic torque) and the lowest tan(delta) were found for EOC-20 with low-octene content at all cross-linking temperatures. Lower peroxide efficiency was observed in the case of the high-octene copolymer. Increased degradation was observed with increasing cross-linking temperature. High-octene EOC was found to be more vulnerable to degradation. According to dynamic mechanical analysis, the storage modulus $\left(\mathrm{M}^{\prime}\right)$ and the glass transition temperature $\left(T_{\mathrm{g}}\right)$ obtained from the tan(delta) peaks were found to decrease with increasing octene content. The differential scanning calorimetry (DSC) results show that the octene content has an inverse effect on the crystallinity $(X)$ and melting point $\left(T_{\mathrm{m}}\right)-$ due to the reduction in the average number of consecutive ethylene units. Creep testing at $150{ }^{\circ} \mathrm{C}$ confirmed the cross-linkability results obtained by RPA and the gel content analyses. Increased $\beta$-scission due to high numbers of tertiary carbon atoms present in the chain has resulted in the poorer cross-linking and inferior properties of high-octene EOC.

Polymer Journal (2013) 45, 651-658; doi:10.1038/pj.2012.189; published online 14 November 2012

Keywords: creep; cross-linking; degradation; DSC; ethylene-octene copolymer

\section{INTRODUCTION}

Thermoplastic elastomers are a special class of materials that possess elastomeric characteristics coupled with the processability of thermoplastics. As a result, thermoplastic elastomers have applications in a wide variety of fields. ${ }^{1}$ Ethylene-octene copolymers (EOCs), which are produced via Dow's INSITE constrained geometry catalyst technology (Dow, Midland, MI, USA), constitute a significant subgroup within this class of materials. ${ }^{2}$ EOC has received much attention because of its uniform distribution of comonomer content, narrow molecular weight distribution, fast mixing, good dispersion properties and excellent processability. ${ }^{3}$ The effectiveness of EOC as a substitute for ethylene propylene diene rubber has been investigated for the production of thermoplastic vulcanizates. ${ }^{4}$ Thermoplastic vulcanizates are being used in various applications, such as cushioning agents, foams, gaskets and sealants, because of their structural regularity and nontoxic composition. ${ }^{5}$

Over the last few years, the modification of polymers by controlled degradation and cross-linking to meet the demands of specialty applications, such as high-temperature mechanical properties and improved thermal and chemical resistance, has attracted much attention. ${ }^{6,7}$ One of the advantages of cross-linked polymers is that heating does not cause them to lose shape, melt or flow. Before cross-linking, the semi-crystalline polymers can be processed and fabricated into a desired shape, while above the polymer's melting temperature $\left(T_{\mathrm{m}}\right)$; after cross-linking, the polymers exhibit the mechanical properties of rubber, even at temperatures that exceed their $T_{\mathrm{m}} \cdot{ }^{8}$ The techniques that are widely used for polymer crosslinking are peroxide cross-linking, ${ }^{9-13}$ cross-linking by irradiation ${ }^{14-18}$ and silane-water cross-linking. ${ }^{19-23}$ Peroxide cross-linking is a major chemical cross-linking method used to cross-link saturated polymers. In this method, peroxides are incorporated in the polymer, below the activation temperature of the peroxide via melt-mixing or extrusion, which is followed by cross-linking at an elevated temperature and pressure.

Many studies have been conducted on the peroxide cross-linking of EOC. Degradation, which takes place during and after cross-linking, is one of the major reasons for the deterioration in the final properties of the cross-linked polymers. Nicolas et al..$^{24}$ compared cross-linking efficiencies and properties of various EOCs that are cross-linked through different techniques. Yang et al. ${ }^{25}$ studied the thermal oxidation of EOC by the rheological method. Although, a vast amount of work has already been performed on the peroxide

${ }^{1}$ Department of Polymer Engineering, Centre of Polymer Systems, Tomas Bata University in Zlin, Zlin, Czech Republic; ${ }^{2}$ Faculty of Humanities, Tomas Bata University in Zlin, Zlin, Czech Republic and ${ }^{3}$ Department of Organic and Polymeric Materials, Tokyo Institute of Technology, Tokyo, Japan

Correspondence: Dr P Svoboda, Department of Polymer Engineering, Centre of Polymer Systems, Tomas Bata University in Zlin, Nam.T.G.Masaryka 5555, 760 01 Zlin, Czech Republic. 
cross-linking of EOCs, little attention has been paid to the degradation during cross-linking and the factors affecting the degradation. The main objective of the current research is to compare two different EOCs on the basis of their cross-linking efficiency and their degradation and mechanical properties.

\section{EXPERIMENTAL PROCEDURE}

In this study, we have used two different EOCs with trade name ENGAGE, supplied by The Dow Chemical Company (Midland, MI, USA). The octene contents of these copolymers were 20 and $35 \mathrm{wt} \%$ for ENGAGE 8450 and 8452, respectively. Their corresponding densities were 0.902 and $0.875 \mathrm{~g} \mathrm{~cm}^{-3}$, respectively, and they have equivalent melt flow index (MFI) values of $3 \mathrm{~g}$ per $10 \mathrm{~min}$. In this article, the two ENGAGE copolymers-ENGAGE 8450 and 8452-are mentioned as EOC-20 and EOC-35, respectively, for the sake of simplicity.

Perkadox BC-40B-PD (dicumyl peroxide (DCP)), which has an active peroxide content of $40 \%$ and was supplied by Akzo Nobel (Amsterdam, the Netherlands), was used for the cross-linking. The half-life time of decomposition $\left(t_{1 / 2}\right)$ at $138^{\circ} \mathrm{C}$ is $1 \mathrm{~h}$, and the specific gravity is $1.53 \mathrm{~g} \mathrm{~cm}^{-3}$ at $23^{\circ} \mathrm{C}$. Various concentrations of peroxide, such as $0.75,1.25$ and $1.75 \mathrm{wt} \%$, with active peroxide contents of $0.3,0.5$ and $0.7 \mathrm{wt} \%$, respectively, were used.

Irganox 1010 (chemical name tetrakis-(methylene-(3,5-di-(tert)-butyl-4hydrocinnamate) methane) was supplied by Ciba Specialty Chemicals (Basel, Switzerland). Irganox 1010, which has a density of $1.15 \mathrm{~g} \mathrm{~cm}^{-3}$, was used as the antioxidant. The antioxidant content was always maintained at a constant level of $0.4 \mathrm{wt} \%$.

EOCs were melt-mixed with peroxide and Irganox 1010 via a Brabender Plasti-corder PL2000 internal mixer (Duisburg, Germany) with a mixing volume of $50 \mathrm{~cm}^{3}$ at $100^{\circ} \mathrm{C}$ and 50 r.p.m. for $10 \mathrm{~min}$. Compounded batches were stored in a freezer at $-18^{\circ} \mathrm{C}$ to avoid unwanted cross-linking during storage.

Cross-linking and degradation were studied using a rubber process analyzer, RPA-2000 (Alpha Technologies, Akron, OH, USA), at various temperatures and the appropriate times. Testing conditions were maintained at an angle of $0.5^{\circ}$ and at a frequency of 100 cycles per minute, which corresponds to $1.667 \mathrm{~Hz}$. The two values of torque obtained during the analysis were $s^{\prime}$ (elastic torque) and $s^{\prime \prime}$ (viscous torque), where $\tan \delta=s^{\prime \prime} / s^{\prime}$.

The gel content of the cross-linked EOC was determined by evaluating the content of the insoluble fraction of the cross-linked material after solvent extraction, according to ASTM D2765-01. Approximately $0.3 \mathrm{~g}$ of cross-linked sample was wrapped in a 120 mesh stainless steel cage and extracted in refluxing xylene, which contains $1 \%$ of antioxidant (Irganox 1010), for $6 \mathrm{~h}$. The sample was then dried in a vacuum at $55^{\circ} \mathrm{C}$ and weighed. The percent gel content was calculated according to the following formula,

$$
\text { Gel content }=\frac{\text { Final weight of sample }}{\text { Initial weight of sample }} \times 100
$$

The thermal properties of the cross-linked EOC samples were analyzed by a PerkinElmer differential scanning calorimetry (DSC)-1 (Waltham, MA, USA). A temperature calibration was performed using an indium standard. A nitrogen atmosphere was employed during the experiment at a heat flow rate of $20 \mathrm{mlmin}^{-1}$. The heating rate used for the DSC experiments was $50{ }^{\circ} \mathrm{Cmin}^{-1}$.

Specimens of approximately $25 \times 3 \times 0.7 \mathrm{~mm}^{3}$ were tested via the dynamic mechanical analysis (DMA) instrument-DMA/SDTA 861e (Mettler-Toledo, Greifensee, Switzerland)—in tensile mode with a frequency of $5 \mathrm{~Hz}$. The specimens were heated at a rate of $3{ }^{\circ} \mathrm{C} \mathrm{min}^{-1}$ in the temperature range from -80 to $170^{\circ} \mathrm{C}$.

Tensile samples were cut out of the cross-linked sheets and were used for the tensile creep experiments according to ISO 899. Creep testing was carried out in a Memmert UFE 400 oven with digital temperature control (Memmert, Schwabach, Germany). Creep was recorded through the glass window using a Sony SLT-A33 camera, capable of HD $1920 \times 1080$ video $(25$ frames per sec) (SONY, Minato, Tokyo, Japan). This video was later analyzed at proper time intervals. The effect of octene content on the creep behavior of peroxide crosslinked EOC was studied at a fixed stress level of $0.1 \mathrm{MPa}$ and $150^{\circ} \mathrm{C}$.

\section{RESULT AND DISCUSSIONS}

Figures 1a and $\mathrm{b}$ show the raw data obtained from RPA, specifically, the real component of the elastic torque, $s^{\prime}$ and $\tan \delta$ for EOC-20 and EOC-35. From this graph, it can be noted that EOC-35 with $35 \mathrm{wt} \%$ octene has lower elastic torque compared with EOC-20, which has a lower-octene content $(20 \mathrm{wt} \%)$. The minimum value of $\mathrm{s}^{\prime}$ represents the processability and the maximum of $s^{\prime}$ contains information about the mechanical properties after cross-linking. The value of $\tan \delta$ after cross-linking is lower for low-octene EOC, which corresponds to better elasticity. Figure 1 shows the data for just one temperature $\left(180^{\circ} \mathrm{C}\right)$ and one peroxide level $(0.5 \mathrm{wt} \%)$.

Figure 2 shows the plot of $s_{\text {max }}^{\prime}$ as a function of cross-linking temperature for the two EOCs. As one can see from the plot, the value
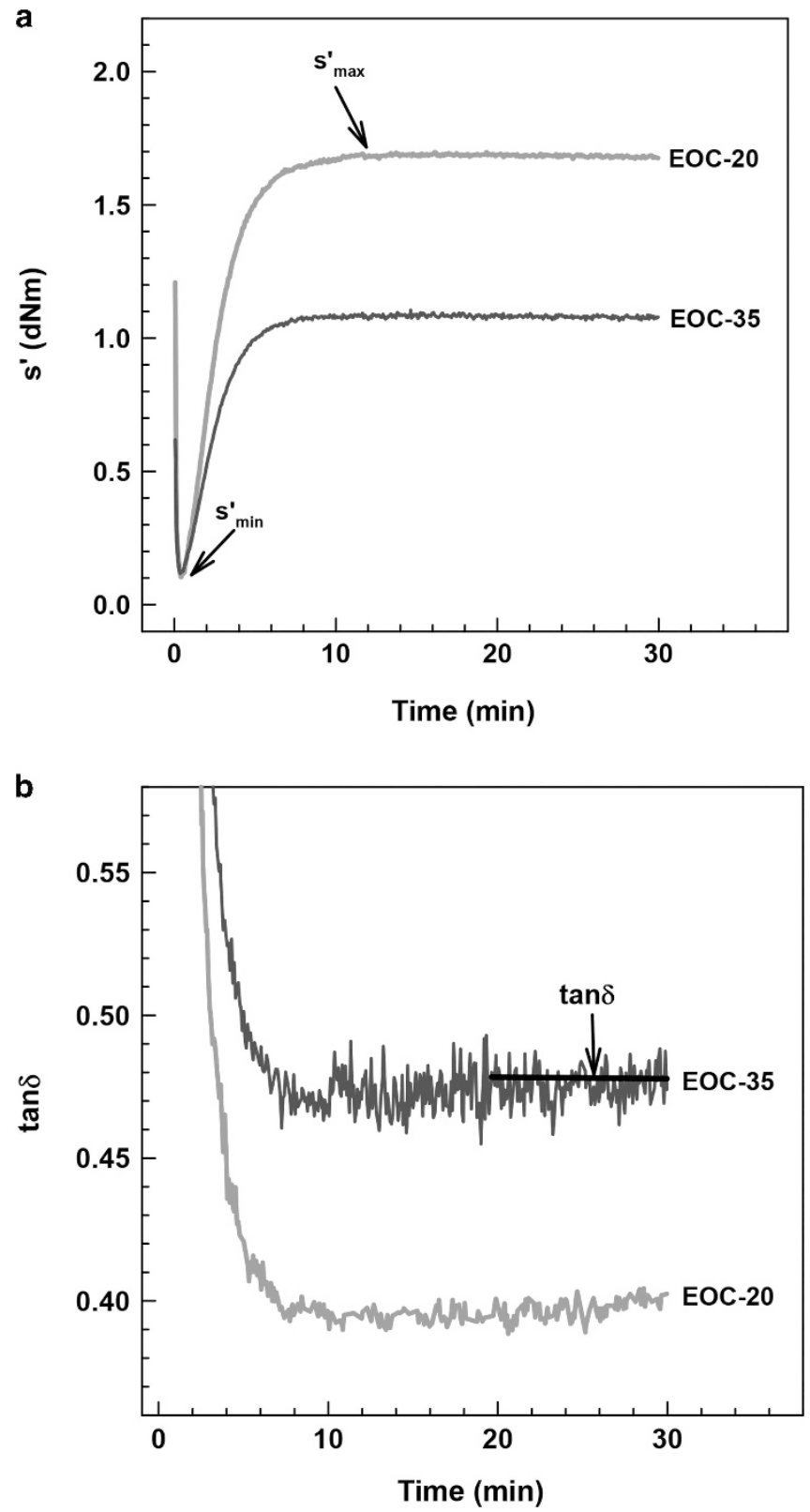

Figure 1 Plots of elastic torque, $\mathrm{s}^{\prime}$ (a) and $\tan \delta$ (b) as a function of cross-linking time for EOC-20 and EOC-35 with $0.5 \mathrm{wt} \%$ of peroxide at $180^{\circ} \mathrm{C}$. A full color version of this figure is available at Polymer Journal online. 


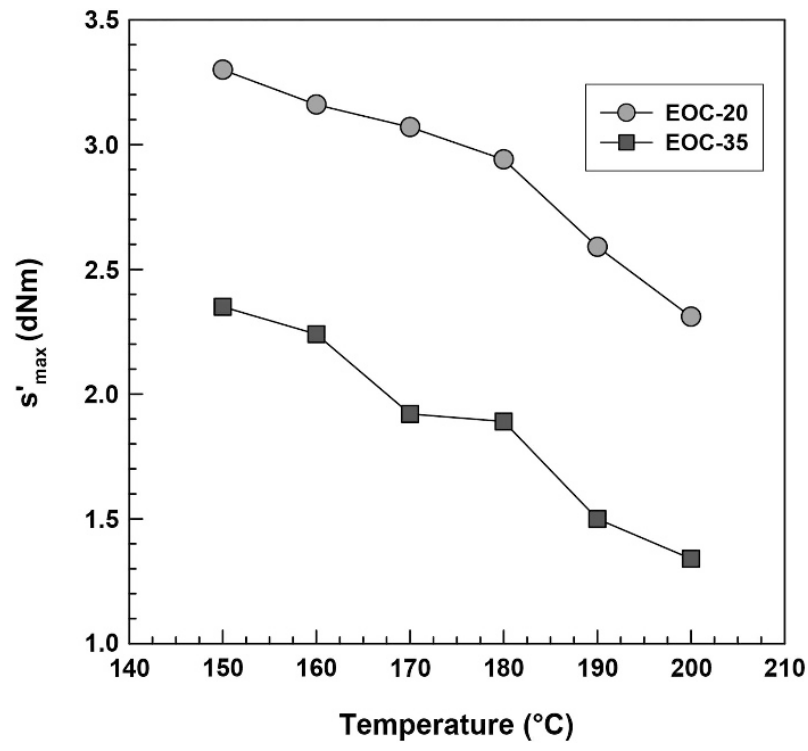

Figure 2 Plot of $s^{\prime}$ max vs temperature for EOC-20 and EOC-35 with $0.7 \mathrm{wt} \%$ of peroxide. A full color version of this figure is available at Polymer Journal online.

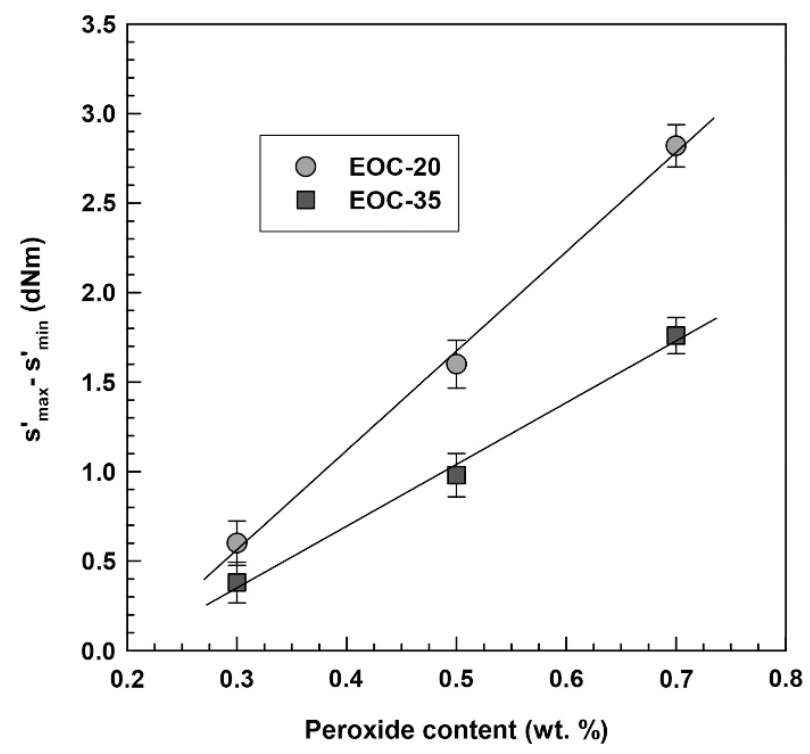

Figure 3 Plot of $s^{\prime}{ }_{\max }-s^{\prime} \min \left(\Delta s^{\prime}\right)$ vs peroxide content at $180^{\circ} \mathrm{C}$ for two different EOCs. A full color version of this figure is available at Polymer Journal online.

of $s_{\text {max }}^{\prime}$ is higher for EOC-20 (lower-octene content). The decrease in the value of $s_{\text {max }}^{\prime}$ that occurs with increasing octene content can be attributed to the increase in branch density. When branching increases, the probability for $\beta$-scission during cross-linking increases, and, thus, so does the probability of degradation. ${ }^{26}$ The value of $s_{\text {max }}^{\prime}$ decreases with cross-linking temperature in both cases. At higher temperatures, the extent of degradation by chain scission is higher, thus the $s_{\text {max }}^{\prime}$ values become lower.

The value of $\Delta s^{\prime}\left(s^{\prime}{ }_{\text {max }}-s_{\text {min }}^{\prime}\right)$ represents the cross-linking efficiency of peroxide, which is defined as the number of moles of chemical cross-links formed per mole of peroxide. ${ }^{27}$ Figure 3 represents the value of $\Delta s^{\prime}$ as a function of peroxide content for EOC-20 and EOC-35, cross-linked at $180^{\circ} \mathrm{C}$. The efficiency of peroxide is

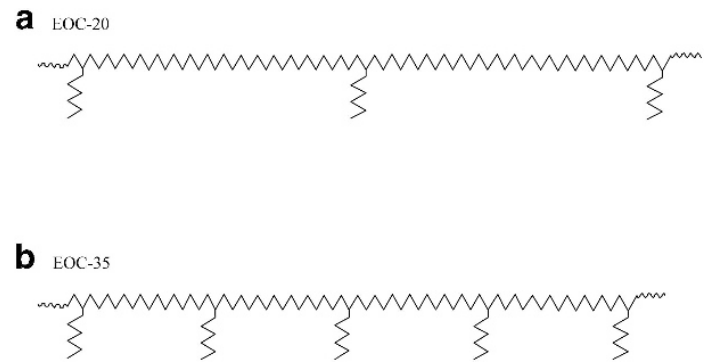

Figure 4 Schematic representation of the structure of two EOCs. (a) EOC-20 and (b) EOC-35.

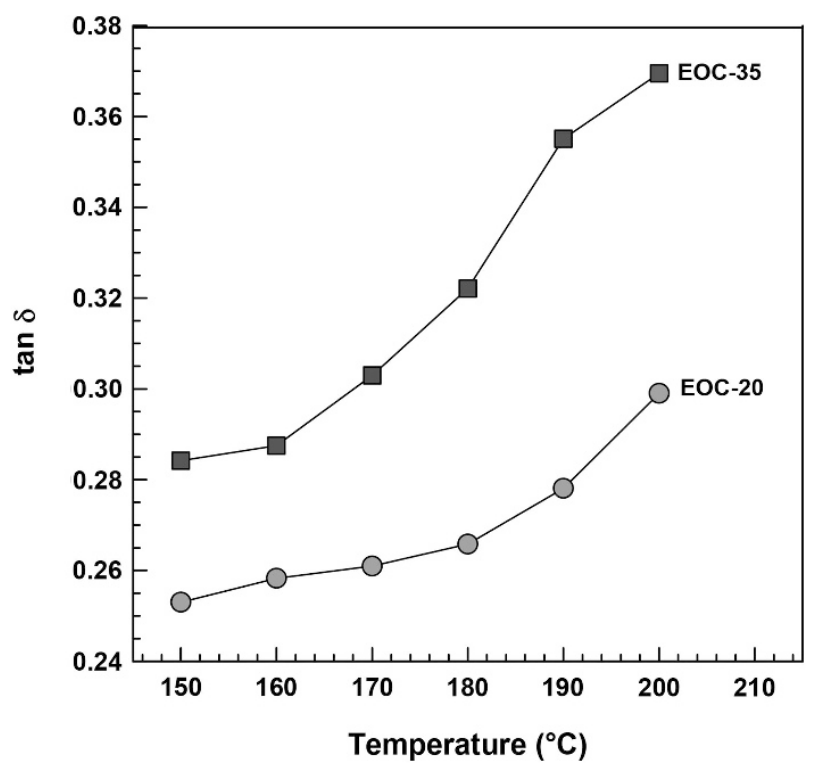

Figure 5 Plot of tan $\delta$ vs temperatures for two different EOCs with 0.7 wt\% peroxide. A full color version of this figure is available at Polymer Journal online.

higher for EOCs with lower-octene content. This effect may result from the difficulty that peroxide-free radicals experience in attacking the main chains due to increased hindrance by octene side groups. This finding can be better understood with the help of the schematic structures of the EOCs, given in Figures $4 \mathrm{a}$ and $\mathrm{b}$. Figure $4 \mathrm{a}$ represents the EOC-20, whereas $4 \mathrm{~b}$ corresponds to EOC-35. Based on the ethylene/octene molar ratio, there are approximately 16 ethylene units per $1 \mathrm{U}$ octene for EOC-20 and 7 ethylene units per $1 \mathrm{U}$ octene for EOC-35. Chain branching generates tertiary carbon atoms, which are more sensitive to scission than other carbon counterparts. In this case (Figure 4), EOC-35 has many more tertiary carbon atoms than EOC-20. The same phenomenon was observed at all cross-linking temperatures. An increase in the number of peroxide-free radicals, in other words, an increase in peroxide content, causes an increase in the value of $\Delta s^{\prime}$ (linear dependency).

Another commercially important value is $\tan \delta\left(\tan \delta=\mathrm{s}^{\prime \prime} / \mathrm{s}^{\prime}\right)$, for which lower values correspond to better elasticity. In Figure 5, $\tan \delta$ values are shown as a function of cross-linking temperature for both EOCs. The values of $\tan \delta$ increased with increasing octene content and temperature. Overall, the best elasticity (lowest $\tan \delta$ values) was found for EOC-20 (lower-octene content) at $150{ }^{\circ} \mathrm{C}$. This result suggests that EOC-20 cross-linked better than EOC-35.

Higher content of octene and a higher concentration of tertiary hydrogen atoms cause greater degradation. At lower temperatures, 
reaching the optimum level of cross-linking requires much more time (at $150^{\circ} \mathrm{C}$, approximately $2 \mathrm{~h}$ is required), and the amount of degradation is extremely low. This result can be observed from the related low $\tan \delta$ values, which correspond to the high elasticities of the materials. EOC-20 exhibits lower tan $\delta$ values than EOC-35 at all temperatures. The difference between these two EOCs is more pronounced at higher temperatures (at $150{ }^{\circ} \mathrm{C}$, the ratio is 0.285 / $0.253=1.126$; at $200^{\circ} \mathrm{C}$, the ratio is $0.37 / 0.30=1.233$ ) when the cross-linking is performed in $2 \mathrm{~min}$. During production, the crosslinking temperature must be selected carefully. Lower temperatures require much more time, but the overall mechanical properties of the resulting materials are much better than those of the polymers crosslinked at higher temperatures.

In Figure 6, the curves of $s^{\prime}$ for EOC-20 showed cross-linking to occur at $180^{\circ} \mathrm{C}$ and $200{ }^{\circ} \mathrm{C}$, using $0.7 \mathrm{wt} \%$ of DCP. The rapid initial increase in the curves shows the progress of the cross-linking reaction, until the curve reaches a maximum. After reaching the maximum, the curve shows a slight decrease (quantitatively evaluated by the linear regression of the degradation slope by Sigmaplot 12 software, Systat Software, Inc., Chicago, IL, USA), caused by the possible chain scission at elevated temperatures. Cross-linking and degradation slopes were calculated for the two copolymers at all temperatures $\left(150-200^{\circ} \mathrm{C}\right)$ and at three peroxide levels.

Cross-linking is greatly influenced by temperature. In fact, crosslinking competes with degradation throughout the entire process at elevated temperature. Of course, higher temperatures and longer time spent at the elevated temperature result in a greater extent of degradation. For this reason, it seems that only cross-linking occurs during the first stage, whereas only degradation occurs later. However, this is not completely true. In the rubber industry, researchers generally recognize three vulcanization curves. (1) At low temperatures, the curve continues to increase, even after very long periods of time $(2 \mathrm{~h})$ (positive value of the slope). (2) The cross-linking curve exhibits a plateau 'marching modulus'. In other words, after reaching its maximum, the $s^{\prime}$ curve maintains a constant value. Degradation is in equilibrium with cross-linking; there is no change in torque $s^{\prime}$ over

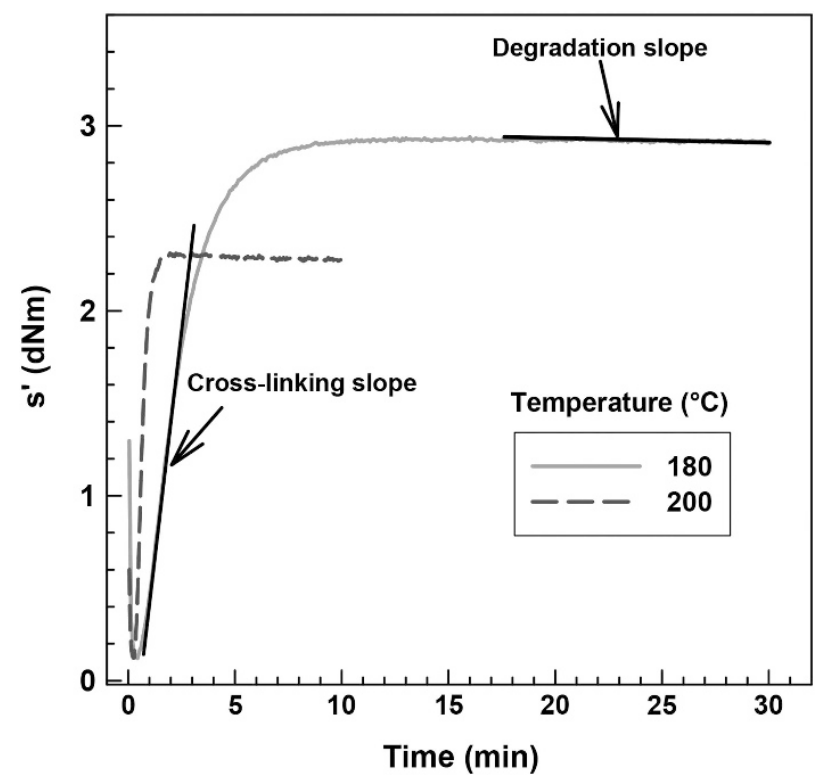

Figure $6 \mathrm{~s}^{\prime}$ as a function of time for EOC-20 cross-linked with 0.7 wt\% of DCP at 180 and $200^{\circ} \mathrm{C}$. A full color version of this figure is available at Polymer Journal online. time (slope value $=0$ ). (3) At high temperatures, the cure curve shows a so-called 'reversion' when degradation takes place. Degradation is manifested by the special shape of the $s^{\prime}$ curve, which after reaching its maximum level, starts to decrease (corresponding to negative value of slope). Bearing in mind the competition between cross-linking and degradation, we have analyzed first the cross-linking slope, a steep increase in the $s^{\prime}$ curve that is also influenced by degradation, and then also the degradation slope (during which cross-linking may also occur), after the $s^{\prime}$ curve has reached its maximum.

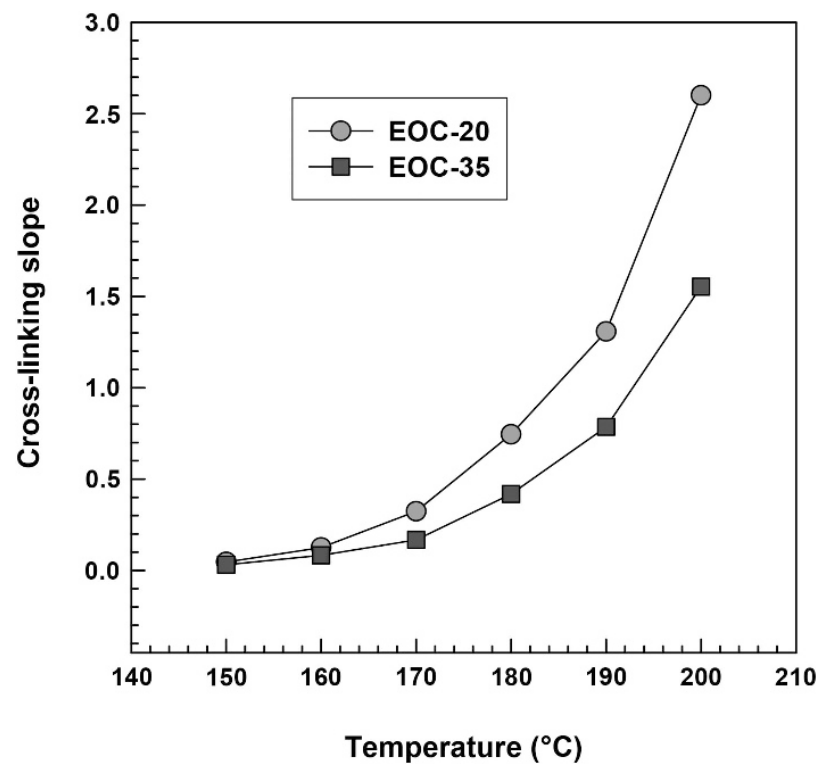

Figure 7 Cross-linking slopes of two different EOCs cross-linked by 0.7 wt $\%$ of DCP. A full color version of this figure is available at Polymer Journal online.

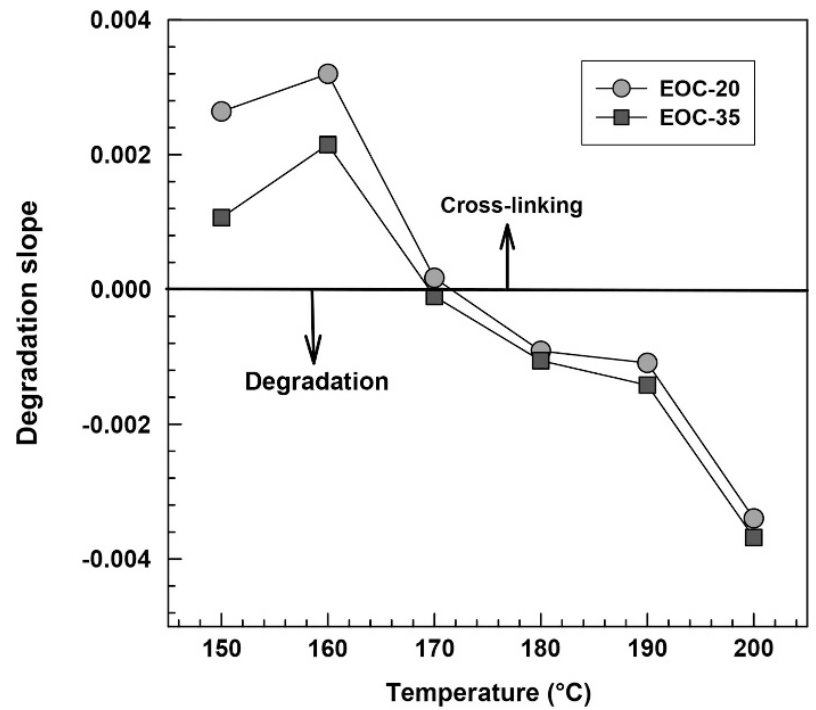

Figure 8 Degradation slope as a function of cross-linking temperature for EOCs cross-linked with 0.7 wt \% of DCP. A full color version of this figure is available at Polymer Journal online. 


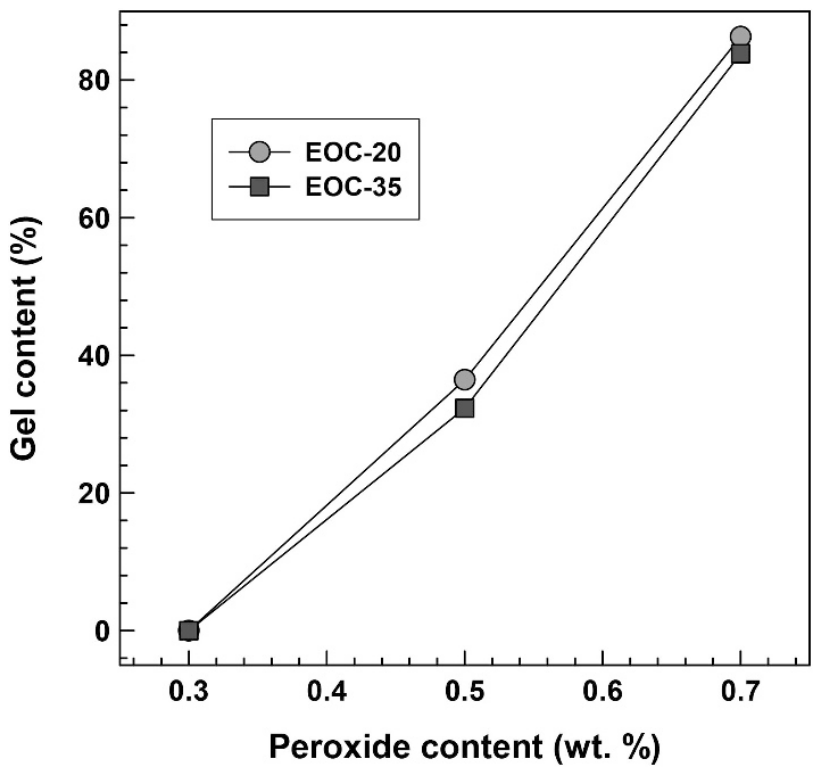

Figure 9 Gel content analysis of cross-linked EOCs. A full color version of this figure is available at Polymer Journal online.

From Figure 7, it can be observed that EOC-20, which has loweroctene content, exhibits higher values for its cross-linking slope, implying a faster cross-linking rate at all temperatures.

The dependence of the values of the degradation slope on temperature is represented in Figure 8. It is clear from the figure that octene content has an influence on the degradation slope value (that is, degradation). As discussed previously, higher-octene content results in a rise in chain branching, which enhances the probability of degradation through $\beta$-scission. As chain branching increases, the number of tertiary carbon atoms increases. Hydrogen atoms on the tertiary carbon atoms can easily be removed and are known as 'labile hydrogen atoms'. When the number of octene units increases, branching and, thus, the probability for degradation via $\beta$-scission also increases.

Another important factor that affects the degradation is the crosslinking temperature. Up to $160^{\circ} \mathrm{C}$, rises in temperature favor the cross-linking reaction, and no or comparatively negligible scission was observed at a temperature of $170^{\circ} \mathrm{C}$. This temperature range can be considered the 'safe temperature range $\left(150-170{ }^{\circ} \mathrm{C}\right)$ for crosslinking, as reported in our previous article. ${ }^{28}$ This finding suggests the possibility of losing the favorable mechanical properties of highoctene EOC that is cross-linked at high temperatures when the time is not precisely kept.

The extent of cross-linking (or cross-linking density) of a polymer can be effectively studied using gel content analysis. Figure 9 represents the influence of peroxide levels on gel content in the case of two EOCs cross-linked at $150{ }^{\circ} \mathrm{C}$. With increasing peroxide content, the gel content also increases. Both samples with $0.3 \mathrm{wt} \%$ of DCP dissolved in xylene completely. Another result from this analysis delineates that for the EOC with higher-octene content, the gel content was found to be slightly lower. The gel content data are in good agreement with the results obtained from RPA. From the gel content analysis, we can strengthen the statement that for higheroctene EOCs, chain scission significantly influences the cross-linking reaction.

The mechanism of the peroxide cross-linking reaction with EOC has been shown in Figure 10a. The free radical produced by the a
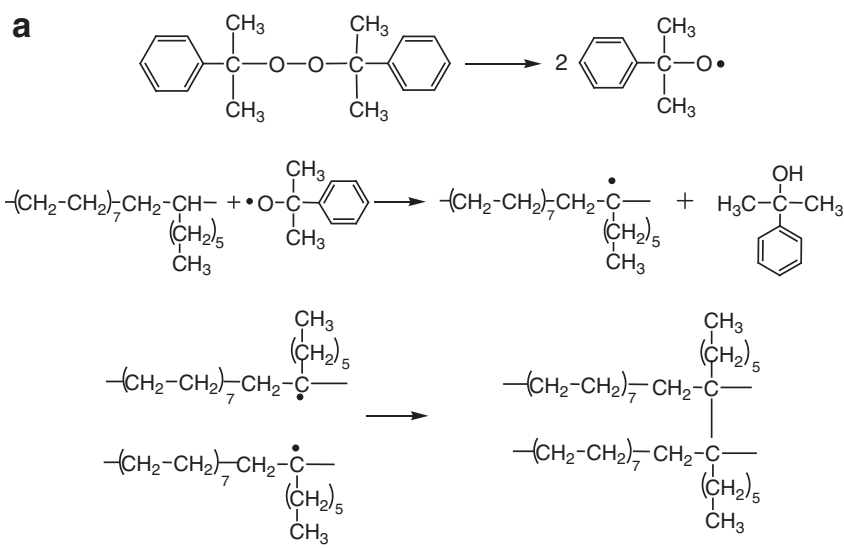

b

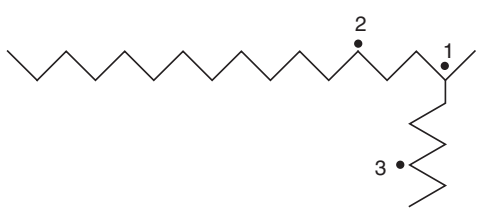

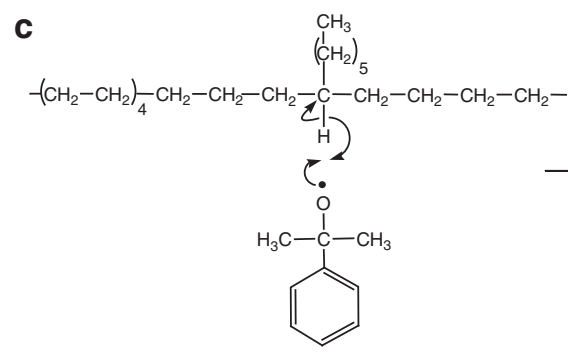

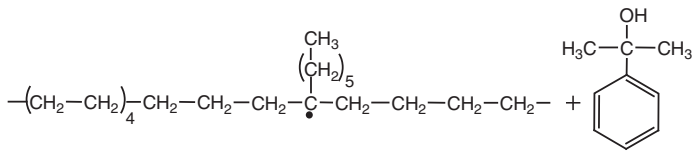
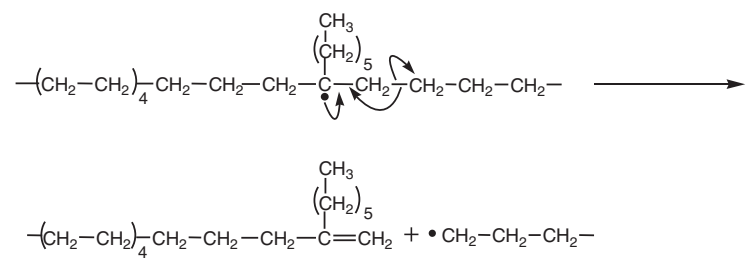

Figure 10 (a) Cross-linking mechanism in EOC/DCP system, (b) three possible sites for free radical attack on EOC chain and (c) possible chain scission mechanism.

homolytic fission of DCP attacks the EOC chain, which results in the creation of a macroradical. Cross-links are formed when chains with macroradical sites combine through a chemical bond, as shown in Figure 10a. This process continues to form a network structure. There are three possibilities for the free radical attack, which are shown in Figure $10 \mathrm{~b}$ and are marked as possibilities 1,2 and 3 according to the priority of each. Position 1, which is a tertiary carbon atom, is a more probable candidate for radical attack (labile hydrogen atom), whereas 2 and 3 are of almost the same probability for radical attack. One possible mechanism of chain scission is schematically represented in Figure 10c.

Mechanical properties were measured by DMA. The DMA data are very useful because the temperature dependence of the storage 


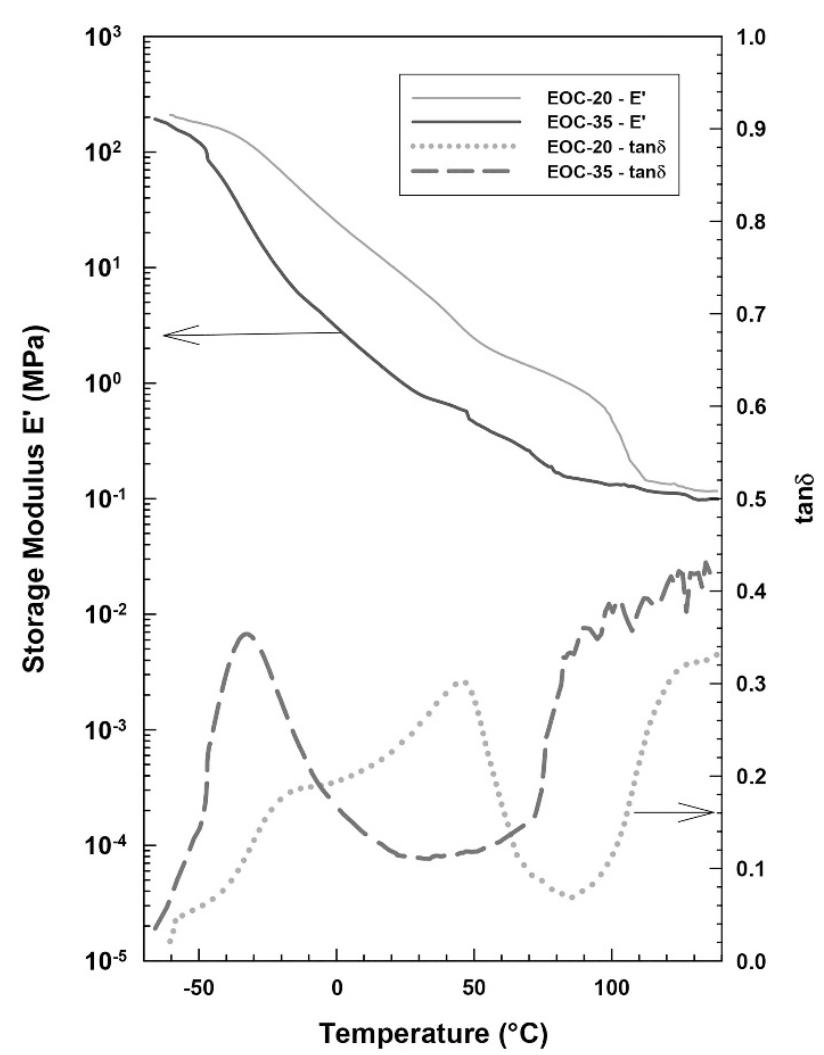

Figure 11 DMA results: storage modulus and $\tan \delta$ of two EOCs cross-linked with $0.7 \mathrm{wt} \%$ of DCP at $170^{\circ} \mathrm{C}$. A full color version of this figure is available at Polymer Journal online.

modulus and $\tan \delta$ can be determined. Figure 11 shows the storage modulus $\left(\mathrm{E}^{\prime}\right)$, and $\tan \delta$ as functions of temperature for EOC-20 and EOC-35, which are cross-linked with $0.7 \mathrm{wt} \%$ of peroxide. The DMA results are not typical. The reason may be a fairly complex structure caused by slight peroxide cross-linking, combined with the small extent of crystallinity (for EOC-20, it is approximately 28\%, whereas for EOC-35, it is approximately $13 \%$-obtained by DSC). EOC-20 seems to exhibit two dispersions, $\alpha$ and $\beta$, whereas EOC-35 exhibits only one main dispersion.

Below $-50{ }^{\circ} \mathrm{C}$, there is a small hint of a glassy plateau, and the storage modulus adopts its highest value. Interestingly enough, below $-60{ }^{\circ} \mathrm{C}$, the storage modulus is not influenced by the octene content (or crystallinity), and the $\mathrm{E}^{\prime}$ values for EOC-20 and EOC-35 were almost the same. In the temperature range -50 to $-20{ }^{\circ} \mathrm{C}$, a remarkable decrease in the storage modulus (usually interpreted as the glass transition temperature, $T_{\mathrm{g}}$ ), which is more pronounced for EOC-35, was observed when $\mathrm{E}^{\prime}$ dropped by one order of magnitude (from 125 to $10 \mathrm{MPa}$ ) and also at $-33^{\circ} \mathrm{C}$, when a clear $\tan \delta$ peak appeared. The occurrence of a $\tan \delta$ peak in literature is usually connected to a 'leather-like' midpoint between the glassy and rubbery states of a polymer, which is frequently interpreted as $T_{\mathrm{g}}$. Concerning EOC-20, the $\mathrm{E}^{\prime}$ decreased, but much less than $\mathrm{E}^{\prime}$ of EOC-35 (from 180 to $70 \mathrm{MPa}$ ); also, $\tan \delta$ does not display a typical peak but instead exhibits a shoulder at $-20{ }^{\circ} \mathrm{C}$. EOC-20 exhibits a large tan $\delta$ peak at $+45^{\circ} \mathrm{C}$, which cannot be interpreted as the glass transition temperature (explanation see below). At higher temperatures $\left(80^{\circ} \mathrm{C}\right.$ for EOC-35 and $110^{\circ} \mathrm{C}$ for EOC-20), the storage modulus reached the lowest level that can be explained by the melting point $T_{\mathrm{m}}$; above
Table 1 DSC analysis of EOCs

\begin{tabular}{lccc}
\hline Sample & $\mathrm{T}_{m}(\mathrm{C})$ & $\Delta H\left(\mathrm{Jg}^{-1}\right)$ & Crystallinity (\%) \\
\hline EOC-20 & 99.9 & 83.0 & 28.6 \\
EOC-35 & 71.0 & 37.8 & 13.0 \\
\hline
\end{tabular}

Abbreviations: DSC, differential scanning calorimetry; EOC, ethylene-octene copolymer.

these temperatures, the tan $\delta$ curve increases enormously due to the increase of the loss modulus $\mathrm{E}^{\prime}$.

The most important observation is that as the comonomer content increases, the storage modulus decreases (the copolymer gets softer and more rubbery). The EOC with lower-octene content has a higher modulus at all temperatures. In the case of $\tan \delta$, two transitions called $\alpha\left(+10\right.$ to $\left.+100^{\circ} \mathrm{C}\right)$ and $\beta\left(+10\right.$ to $\left.-70^{\circ} \mathrm{C}\right)$ can be observed. According to the literature, the motion of $\mathrm{CH}_{2}$ units of polyethylene within the crystal lattice results in an $\alpha$-transition, whereas the motion of branched structures in the amorphous phase causes the $\beta$-transition. ${ }^{29}$ The comonomer content of EOC affects both of these transitions. In the case of high-octene EOC (low crystallinity), an $\alpha$-transition is absent. At the same time, the $\alpha$-transition is more prominent for low-octene EOC.

Crystallinity decreases with increasing octene content, as proven by the DSC results (Table 1). Similar observations have been made by Simanke et al. $^{30}$ for low-octene content EOCs without any cross-linking. They reported that increases in the comonomer content result in decreases in the average number of consecutive ethylene units and, thus, the crystallizable portion of the copolymer reduces. This effect ultimately causes a decrease in crystallinity.

From the $\tan \delta$ curve, it is clear that the $\beta$-transition temperature shifted to lower temperatures as the octene content increased. The peak position of the $\beta$-transition corresponds to the $T_{\mathrm{g}}$ of the amorphous phase. ${ }^{31}$ This decrease in $T_{\mathrm{g}}$ with increasing octene content is due to an increase in the amorphous portion. This result is of significant industrial importance.

To support the above-claimed conclusions, we also performed measurements of the mechanical properties above the EOC melting points. Below $T_{\mathrm{m}}$, the strength of cross-linked EOC comes from crystal lamellae that act as tie points for amorphous chains, and also from cross-linking. To see the influence of cross-linking, the mechanical properties must simply be measured above $T_{\mathrm{m}}$ of the semi-crystalline polymer.

High-density polyethylene exhibits nearly no branching and its chain can freely arrange by folding into a crystal lamella. Therefore, high-density polyethylene has a rather high melting point $T_{\mathrm{m}}$ (approximately $130{ }^{\circ} \mathrm{C}$ ) and high stiffness (for example, at $25^{\circ} \mathrm{C} \mathrm{E}^{\prime}$ is approximately $1000 \mathrm{MPa}$ ). Octene contributes six methylene groups to the main chain in the form of branches. In contrast to isotactic polypropylene (with high crystallinity and stiffness), of which the branches are short and regularly arranged, the branches of EOC are much longer; the distance between the branches is also greater in EOC, when compared with isotactic polypropylene. Longer and more distantly spaced branches prevent chain folding into a crystal lamella. Higher-octene content and lower $T_{\mathrm{m}}$ were found to correspond to lower crystallinity and greater material softness. Though the storage modulus of EOC- 20 at $25^{\circ} \mathrm{C}$ was approximately $8 \mathrm{MPa}$, the storage modulus of EOC-35, which has higher branching density, was found to be around only $1 \mathrm{MPa}$. EOC-35 is much softer than EOC-20. This situation is similar to that of the introduction of propylene comonomer to ethylene, which generates ethylene-propylene rubber; 


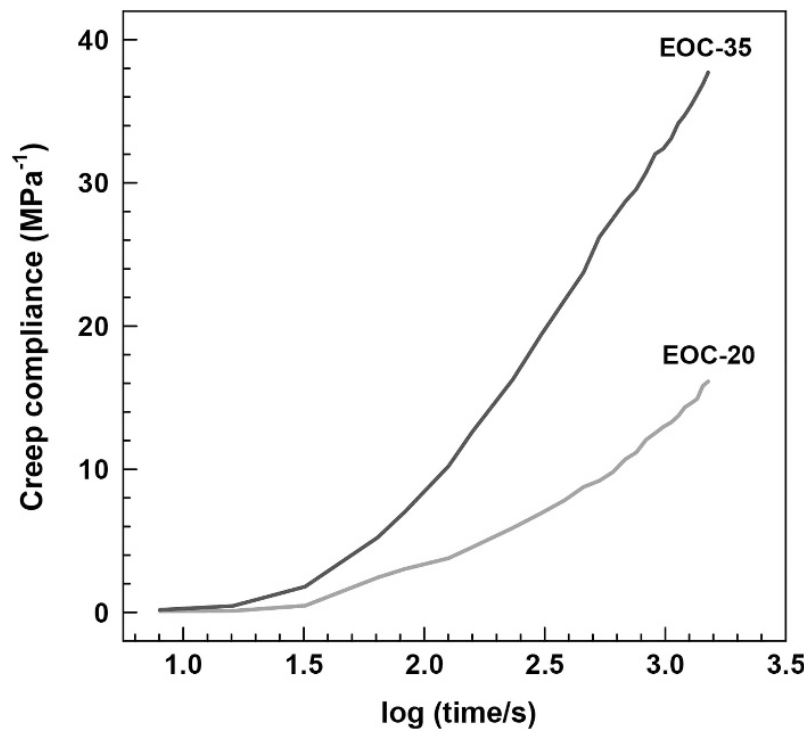

Figure 12 Creep compliance curves at $150^{\circ} \mathrm{C}$ and $0.1 \mathrm{MPa}$ stress for EOCs with 0.7 wt\% DCP. A full color version of this figure is available at Polymer Journal online.

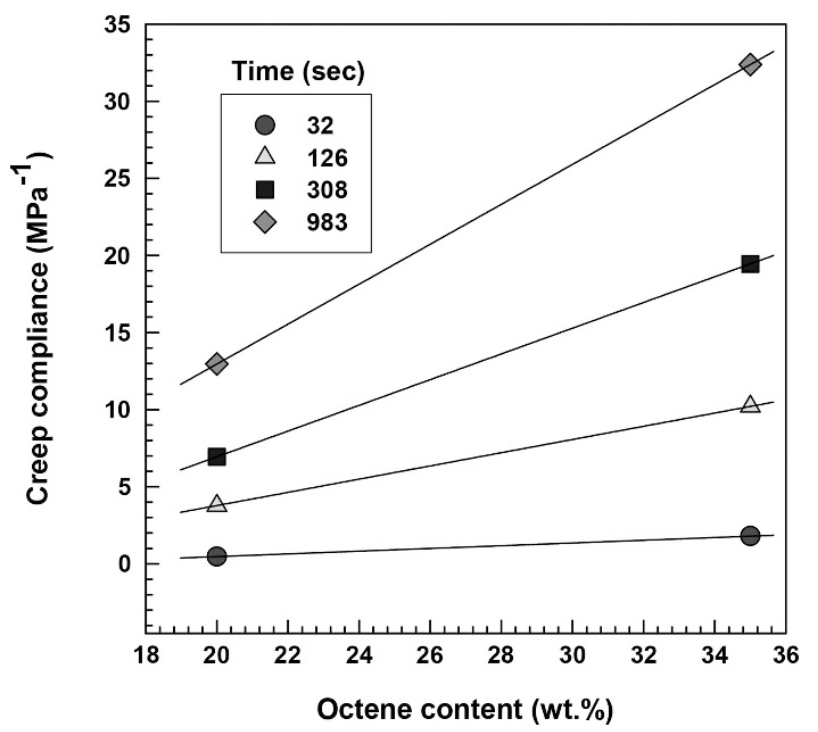

Figure 13 Creep compliance as a function of octene content at $150^{\circ} \mathrm{C}$ and $0.1 \mathrm{MPa}$ stress for EOCs cross-linked with $0.7 \mathrm{wt} \%$ DCP. A full color version of this figure is available at Polymer Journal online.

ethylene-propylene rubber is much softer and also has a much lower crystallinity compared with pure polyethylene.

To determine the $T_{\mathrm{m}}$ of the EOCs investigated, DSC experiments were conducted. The results are summarized in Table 1 . The melting point $\left(T_{\mathrm{m}}\right)$ and crystallinity $(X)$ were shown to decrease with increasing octene content. Based on this analysis, the temperature for high-temperature creep testing was set to $150{ }^{\circ} \mathrm{C}$, the temperature at which all the crystals are melted. The results are shown in Figures 12 and 13. From Figure 12, one can observe that EOC with lower-octene content has lower creep compliance values than EOC with higher-octene levels. EOC-35 underwent a higher creep than EOC-20 at all times during the measurement because of its lesser extent of cross-linking. Creep compliance values after different times were evaluated and plotted in Figure 13. Copolymer with loweroctene content exhibited lower creep values at all times. These results agree with the RPA and gel content results, which were discussed earlier.

\section{CONCLUSIONS}

Two EOCs with different octene contents but the same initial MFI value were cross-linked using DCP at different temperatures. The influence of octene content, peroxide level and temperature on crosslinking, degradation and high-temperature creep were studied. The cross-linking efficiency of EOCs was greatly influenced by the octene content, peroxide level and cross-linking temperature. Better crosslinking was achieved for EOC with lower-octene content. According to $\tan \delta$ analysis, the best elastic properties were observed for EOC-20 (having $20 \mathrm{wt} \%$ octene) cross-link at low temperature $\left(150^{\circ} \mathrm{C}\right)$. An increase in cross-linking temperature (above $170{ }^{\circ} \mathrm{C}$ ) resulted in increased degradation for both EOCs. However, high-octene copolymer (EOC-35) was more vulnerable to degradation, which can be attributed to the increased number of tertiary carbon atoms compared with that of the low-octene EOC. The gel content and high-temperature creep analyses confirm the conclusion that EOC-20 (with low-octene content) underwent better cross-linking. The crystallinity and melting point of the EOCs decreased with increasing octene content, as illustrated by DSC analysis. DMA revealed lower $T_{\mathrm{g}}$ and lower modulus for copolymers with higher-octene content.

\section{ACKNOWLEDGEMENTS}

This work was supported by the Internal Grant Agency (IGA/FT/2012/040) and also by the Operational Programme Research and Development for Innovations co-funded by the European Regional Development Fund (ERDF) and the national budget of the Czech Republic within the framework of the Center of Polymer Systems project (registration number: CZ.1.05/2.1.00/ 03.0111).

1 Holden, G., Kricheldorf, H. R. \& Quirk, R. P. (eds). Thermoplastic Elastomers (Hanser Gardner Publications, Munich, 2004).

2 Bensason, S., Minick, J., Moet, A., Chum, S., Hiltner, A. \& Baer, E. Classification of homogeneous ethylene-octene copolymers based on comonomer content. J. Polym. Sci. Pol. Phys. 34, 1301-1315 (1996).

3 Angel, C. M., Norky, V., Isabel, G. -M., Carlos, M. J. \& Maria, P. J. Characterization of electron beam irradiation blends based on metallocene ethylene-1-octene copolymer. Polym. Sci. Pol. Phys. 45, 2432-2440 (2007).

4 Babu, R. R., Singha, N. K. \& Naskar, K. Phase morphology and melt rheological behavior of uncross-linked and dynamically cross-linked polyolefin blends: role of macromolecular structure. Polym. Bull 66, 95-118 (2011).

5 Nayak, N. C. \& Tripathy, D. K. Effect of aluminium silicate filler on morphology and physical properties of closed cell microcellular ethylene-octene copolymer. J. Mater. Sci. 37, 1347-1354 (2002).

6 Zhou, W. \& Zhu, S. ESR study of peroxide-induced cross-linking of high density polyethylene. Macromolecules 31, 4335-4341 (1998).

7 Sirisinha, K. \& Meksawat, D. Changes in properties of silane-water cross-linked metallocene ethylene-octene copolymer after prolonged cross-linking time. J. Appl. Polym. Sci. 93, 901-906 (2004).

8 Khonakdar, H. A., Morshedian, J., Wagenknecht, U. \& Jafari, S. H. An investigation of chemical cross-linking effect on properties of high-density polyethylene. Polymer 44, 4301-4309 (2003).

9 Anbarasan, R., Babot, O. \& Maillard, B. Cross-linking of high-density polyethylene in the presence of organic peroxides. J. Appl. Polym. Sci. 93, 75-81 (2004).

10 Ghosh, P., Dev, D. \& Chakrabarti, A. Reactive melt processing of polyethylene: effect of peroxide action on polymer structure, melt rheology and relaxation behaviour. Polymer 38, 6175-6180 (1997).

11 Machado, A. V., Covas, J. A. \& Duin, M.V. Monitoring polyolefin modification along the axis of a twin screw extruder. I. Effect of peroxide concentration. J. Appl. Polym. Sci. 81, 58-68 (2001)

12 Parent, J. S., Tripp, M. \& Dupont, J. Selectivity of peroxide-initiated graft modification of ethylene copolymers. Polym. Eng. Sci. 43, 234-242 (2003).

13 Ratner, S., Weinberg, A. \& Marom, G. Morphology and mechanical properties of crosslinked PE/PE composite materials. Polym. Composite 24, 422-427 (2003). 
14 Basfar, A. A., Mosnácek, J., Shukri, T. M., Bahattab, M. A., Noireaux, P. \& Courdreuse A. Mechanical and thermal properties of blends of low-density polyethylene and ethylene vinyl acetate cross-linked by both dicumyl peroxide and ionizing radiation for wire and cable applications. J. Appl. Polym. Sci. 107, 642-649 (2008).

15 Benson, R. S., Moore, E. A., Martinez-Pardo, M. E. \& Zaragoza, D. L. Effect of gamma irradiation on ethylene-octene copolymers produced by constrained geometry catalyst. Nucl. Instrum. Meth. B 151, 174-180 (1999).

16 Luan, S. F., Shia, H., Yao, Z. H., Wang, J. W., Song, Y. X. \& Yin, J. H. Effect of electron beam irradiation sterilization on the biomedical poly (octene-co-ethylene)/polypropylene films. Nucl. Instrum. Meth. B 268, 1474-1477 (2010).

17 Shen, F. -W., Mckellop, H. A. \& Salovey, R. Irradiation of chemically cross-linked ultrahigh molecular weight polyethylene. J. Polym. Sci. Pol. Phys. 34, 1063-1077 (1996).

18 Tretinnikov, O. N., Ogata, S. \& Ikada, Y. Surface cross-linking of polyethylene by electron beam irradiation in air. Polymer 39, 6115-6120 (1998).

19 Barzin, J., Azizi, H. \& Morshedian, J. Preparation of silane-grafted and moisture crosslinked low density polyethylene: Part I: factors affecting performance of grafting and cross-linking. Polym-Plast. Technol. 45, 979-983 (2006).

20 Fabris, F. W., Stedile, F. C., Mauler, R. S. \& Nachtigall, S. M. B. Free radical modification of LDPE with vinyltriethoxysilane. Eur. Polym. J. 40, 1119-1126 (2004).

21 Garnier, L., Duquesne, S., Casetta, M., Lewandowski, M. \& Bourbigot, S. Melt spinning of silane-water cross-linked polyethylene-octene through a reactive extrusion process. React. Funct. Polym. 70, 775-783 (2010).

22 Kuan, H. -C., Kuan, J. -F., Ma, C. -C. M. \& Huang, J. -M. Thermal and mechanical properties of silane- grafted water cross-linked polyethylene. J. Appl. Polym. Sci. 96, 2383-2391 (2005)
23 Yang, S., Song, G., Zhao, Y., Yang, C. \& She, X. Mechanism of a one-step method for preparing silane grafting and cross-linking polypropylene. Polym. Eng. Sci. 47, 1004-1008 (2007).

24 Nicolás, J., Ressia, J. A., Vallés, E. M., Merino, J. C. \& Pastor, J. M. Characterization of metallocene ethylene-1-octene copolymers with high comonomer content cross-linked by dicumyl peroxide or $\beta$-radiation. J. Appl. Polym. Sci. 112, 2691-2700 (2009).

25 Yang, K., Yu, W. \& Zhou, C. X. Thermal oxidation of metallocene-catalyzed poly( ethylene octene) by a rheological method. J. Appl. Polym. Sci. 105, 846-852 (2007).

26 Paul, S. \& Kale, D. D. Impact modification of polypropylene copolymer with a polyolefinic elastomer. J. Appl. Polym. Sci. 76, 1480-1484 (2000).

27 Basuli, U., Chaki, T. K. \& Naskar, K. Mechanical properties of thermoplastic elastomers based on silicone rubber and an ethylene-octene copolymer by dynamic vulcanization. J. Appl. Polym. Sci. 108, 1079-1085 (2008).

28 Svoboda, P., Poongavalappil, S., Theravalappil, R., Svobodova, D., Mokrejs, P. Kolomaznik, K., Ougizawa, T. \& Inoue, T. Cross-linking of ethylene-octene copolymer (EOC) by dicumyl peroxide (DCP). J. Appl. Polym. Sci. 121, 521-530 (2011).

29 Al-Malaika, S., Peng, X \& Watson, H. Metallocene ethylene-1-octene copolymers: Influence of comonomer content on thermo-mechanical, rheological, and thermooxidative behaviours before and after melt processing in an internal mixer. Polym Degrad. Stabil. 91, 3131-3148 (2006).

30 Simanke, A. G., Galland, G. B., Freitas, L., Jornada, J. A. H. d., Quijada, R. \& Mauler R. S. Influence of the comonomer content on the thermal and dynamic mechanical properties of metallocene ethylene/1-octene copolymers. Polymer 40, 5489-5495 (1999).

31 Khanna, Y. P., Turi, E. A., Taylor, T. J., Vickroy, V. V. \& Abbott, R. F. Dynamic mechanical relaxations in polyethylene. Macromolecules 18, 1302-1309 (1985). 